\title{
Enzymes Involved in Naproxen Degradation by Planococcus sp. S5
}

\author{
DANUTA WOJCIESZYŃSKA, DOROTA DOMARADZKA, KATARZYNA HUPERT-KOCUREK \\ and URSZULA GUZIK*
}

Department of Biochemistry, Faculty of Biology and Environment Protection, University of Silesia in Katowice, Katowice, Poland

Submitted 30 October 2015, revised 8 January 2016, accepted 10 January 2016

\begin{abstract}
Naproxen is a one of the most popular non-steroidal anti-inflammatory drugs (NSAIDs) entering the environment as a result of high consumption. For this reason, there is an emerging need to recognize mechanisms of its degradation and enzymes engaged in this process. Planococcus sp. S5 is a gram positive strain able to degrade naproxen in monosubstrate culture (27\%). However, naproxen is not a sufficient growth substrate for this strain. In the presence of benzoate, 4-hydroxybenzoic acid, 3,4-dihydroxybenzoic acid or vanillic acid as growth substrates, the degradation of $21.5 \%, 71.71 \%, 14.75 \%$ and $8.16 \%$ of naproxen was observed respectively. It was shown that the activity of monooxygenase, hydroxyquinol 1,2-dioxygenase, protocatechuate 3,4-dioxygenase and protocatechuate 4,5-dioxyegnase in strain S5 was induced after growth of the strain with naproxen and 4-hydroxybenzoate. Moreover, in the presence of naproxen activity of gentisate 1,2-dioxygenase, enzyme engaged in 4-hydroxybenzoate metabolism, was completely inhibited. The obtained results suggest that monooxygenase and hydroxyquinol 1,2-dioxygenase are the main enzymes in naproxen degradation by Planococcus sp. S5.
\end{abstract}

Ke y words: Planococcus, biodegradation, naproxen, enzymes induction, aromatic plant compounds

\section{Introduction}

In recent years, non-steroidal anti-inflammatory drugs (NSAIDs) have been widely detected in the environment. These biologically active compounds and their continuous inflow into the environment may lead to their accumulation in the environment and chronic exposure of organisms. As a result, this may cause potential negative effects on living organisms. While the transformation mechanisms of non-steroidal antiinflammatory drugs in the human body and in other animals have been extensively studied, the degradation of these drugs by bacteria has been seldom investigated and remains largely unknown (Quintana et al., 2005; Marco-Urrea et al., 2010; Wojcieszyńska et al., 2014). It is suggested that the transformation of naproxen by Trametes versicolor or activated sludge may occur by 2-(6-hydroxynaphthalen-2-yl)propanoic acid and 1-(6-methoxynaphthalen-2-yl)ethanone formation (Quintana et al., 2005; Marco-Urrea et al., 2010; Lahti and Oikari, 2011). Marco-Urrea et al. (2010) suggested participation of laccase and cytochrome P-450 system in biotransformation of this drug in fungi. Among bacteria, only Stenotrophomonas maltophilia KB2 is known to be able to cometabolically degrade naproxen (Wojcieszyńska et al., 2014). After growth of strain KB2 on naproxen activity of phenol monooxygenase, naphthalene dioxygenase, hydroxyquinol 1,2-dioxygenase and gentisate 1,2-dioxygenase was observed. It suggests that degradation of this compound consists in its hydroxylation and aromatic ring cleavage (Wojcieszyńska et al., 2014). In monosubstrate culture naproxen is degraded by strain KB2 with low efficiency. The addition of a carbon source, such as glucose, acetate or powdered milk, increases the level of naproxen degradation (Quintana et al., 2005; Lahti and Oikari, 2011; Wojcieszyńska et al., 2014). However, the non-aromatic substrates do not induce enzymes of aromatic ring degradation/transformation pathways. It is observed that the introduction of aromatic compounds (e.g. phenol) as an additional carbon source increase the degradation of toxic, persistent aromatic compounds (Kulkarni and Chaudhari, 2006; Greń et al., 2010; Wojcieszyńska et al., 2014). However, the introduction of phenol or its derivatives into the environment may constitute an additional ballast and disturb ecological balance. Therefore, a good alternative seems to be the use of naturally occurring aromatic compounds, such as protocatechuic

\footnotetext{
* Corresponding author: U. Guzik, Department of Biochemistry, Faculty of Biology and Environment Protection, University of Silesia in Katowice, Katowice, Poland; e-mail: urszula.guzik@us.edu.pl
} 
acid produced by Prunus domestica, Melissa officinalis or Vitis vinifera or vanillic acid identified in Juglans regia or Chenopodium murales (Ghareib et al., 2010; Kakkar and Bais, 2014). The objective of our study is to examine the ability of Planococcus sp. S5 to degrade naproxen in either mono- or disubstrate cultures with plant aromatic compounds as growth substrates. Planococcus sp. S5 was chosen for this study since it degrades salicylate (Łabużek et al., 2003), which is not only the intermediate of naphthalene degradation and mimetic of naproxen, but also belongs to non-steroidal antiinflammatory drugs. Additionally, the aim of this study is to identify enzymes engaged in naproxen degradation by Planococcus sp. S5 in cometabolic conditions.

\section{Experimental}

Materials and Methods

Media and culture conditions. Planococcus sp. S5 was routinely cultivated in BBL nutrient broth at $30^{\circ} \mathrm{C}$ and $130 \mathrm{rpm}$ for 24 hours. Then $6 \mathrm{mg} / \mathrm{l}$ naproxen was added to the culture. After 48 hours, cells were harvested by centrifugation $\left(5.000 \times \mathrm{g}\right.$ at $4^{\circ} \mathrm{C}$ for $\left.15 \mathrm{~min}\right)$, washed with fresh sterile medium and used as inoculum. Degradation of naproxen in a monosubstrate, as well as cometabolic systems, was performed in $500 \mathrm{ml}$ Erlenmeyer flasks containing $250 \mathrm{ml}$ of the mineral salts medium (Greń et al., 2010) inoculated with cells to a final optical density of about 1.5 and 0.5 at $\lambda=600 \mathrm{~nm}$ (OD600) for the monosubstrate and cometabolic systems, respectively. For degradation experiments two control cultures were prepared. The uninoculated control (I) consisted of $250 \mathrm{ml}$ of sterile mineral salts medium, while the heatkilled control (II) consisted of $250 \mathrm{ml}$ of autoclaved culture prepared under conditions identical to those of the experimental cultures. Naproxen was added to each flask to obtain a final concentration of $6 \mathrm{mg} / \mathrm{l}$, and all cultures were incubated with shaking at $30^{\circ} \mathrm{C}$ for 28 days.

For studies on the cometabolic transformation of naproxen, as well as the induction of enzymes, $3 \mathrm{mM}$ aromatic compound of plant origin: benzoate (BA), 4-hydroxybenzoic acid (4-HB), 3,4-dihydroxybenzoic acid (3,4-DHB) or vanillic acid (VA) was added. Cultures in $250 \mathrm{ml}$ of sterile mineral salt medium supplemented with appropriate growth substrate and $6 \mathrm{mg} / \mathrm{l}$ naproxen were inoculated with cells to a final optical density of about 0.5 at $\lambda=600 \mathrm{~nm}$ (OD600), and incubated at $30^{\circ} \mathrm{C}$ with shaking at $130 \mathrm{rpm}$. If the complete degradation of the suitable growth substrate was observed, a successive dose of plant aromatic compound was introduced and the culture was left for incubation until it reached OD600 $=1.0$. All cultures were grown in triplicate.
Analytical methods. To study the degradation of naproxen, $1 \mathrm{ml}$ samples were taken periodically (every 7 days) from the culture medium and centrifuged $(6.000 \times \mathrm{g}, 15 \mathrm{~min})$. The concentration of aromatic substrates in the culture supernatant was determined by HPLC (Merck HITACHI) equipped with a LiChromospher ${ }^{\circledast}$ RP-18 column $(4 \times 250 \mathrm{~mm})$, liChroCART ${ }^{\circledast}$ 250-4 Nucleosil 5 C18 and a DAD detector (Merck HITACHI). The mobile phase was acetonitrile and $1 \%$ acetic acid $(50: 50 \mathrm{v} / \mathrm{v})$ at a flow rate of $1 \mathrm{ml} / \mathrm{min}$. The detection wavelength was set at $260 \mathrm{~nm}$. Naproxen and plant aromatic compounds in the supernatant were identified and quantified by comparing the HPLC retention times and UV-visible spectra with those of the external standards.

Preparation of cell extracts. After 28 days in culture, cells of Planococcus sp. S5 were harvested by centrifugation $\left(4.500 \times \mathrm{g}\right.$ for $15 \mathrm{~min}$ at $\left.4^{\circ} \mathrm{C}\right)$ and the pellet was washed with $50 \mathrm{mM}$ phosphate buffer, $\mathrm{pH} 7.0$, and resuspended in the same buffer. Cell-free extracts were prepared by sonication of the whole cell suspension ( 6 times for $15 \mathrm{~s}$ ) and centrifugation at $9.000 \times \mathrm{g}$ for $30 \mathrm{~min}$ at $4^{\circ} \mathrm{C}$. Clear supernatant was used as a crude cell extract for enzyme assays.

Enzyme assays. Monooxygenase activity was determined spectrophotometrically by measuring $\mathrm{NADH}$ oxidation $\left(\varepsilon^{340}=6.220 / \mathrm{Mcm}\right)$ (Divari et al., 2003). In order to determine the activity of dioxygenase-catalysed dihydroxylation, the formation of cis,cis-dihydrodiol was measured at $262 \mathrm{~nm}\left(\varepsilon^{262}=8.230 / \mathrm{M} \mathrm{cm}\right)$ (Cidaria et al., 1994). The activity of catechol 1,2-dioxygenase was measured spectrophotometrically by the formation of cis,cis-muconic acid at $260 \mathrm{~nm}$ $\left(\varepsilon^{260}=16.800 / \mathrm{Mcm}\right)$. In order to determine catechol 2,3-dioxygenase activity, the formation of 2-hydroxymuconic semialdehyde was measured at $375 \mathrm{~nm}$ $\left(\varepsilon^{375}=36.000 / \mathrm{M} \mathrm{cm}\right)$ (Wojcieszyńska et al., 2011). The activity of protocatechuate 3,4-dioxygenase was assayed by measuring oxygen consumption (Hou et al., 1976). The activity of protocatechuate 4,5-dioxygenase was measured spectrophotometrically by the formation of 2-hydroxy-4-carboxymuconic semialdehyde at $410 \mathrm{~nm}$ $\left(\varepsilon^{410}=9.700 / \mathrm{Mcm}\right)$ (Wojcieszyńska et al., 2011). In order to determine gentisate 1,2-dioxygenase activity, the formation of maleylpyruvate was measured at $330 \mathrm{~nm}$ $\left(\varepsilon^{330}=10.800 / \mathrm{M} \mathrm{cm}\right)$ (Feng et al., 1999). The activity of hydroxyquinol 1,2-dioxygenase was measured spectrophotometrically by the formation of maleylacetate at $243 \mathrm{~nm}\left(\varepsilon^{243}=44.520 / \mathrm{M} \mathrm{cm}\right)$ (Wei et al., 2010).

One unit of enzyme activity was defined as the amount of enzyme required to generate $1 \mu \mathrm{mol}$ of product per minute. Protein concentration in the crude extract was determined by the Bradford method using bovine serum albumin as a standard (Wojcieszyńska et al., 2011). All experiments were performed in three 
replicates. The values of enzyme activities were analyzed by one-way ANOVA $(\mathrm{p}<0.05)$ using STATISTICA 10.0 PL software package.

\section{Results and Discussion}

Naproxen degradation in mono- and disubstrate cultures. Naproxen belongs to the polar acidic drugs that are often used by human population as a nonsteroidal anti-inflammatory drug without prescription (Grenni et al., 2014). For this reason, a great amount of naproxen or its metabolites is excreted and enters sewage treatment plants, where they are barely reduced and, consequently, released into the environment. Although these compounds are microcontaminants, detected in the range $0.01-2.6 \mu \mathrm{g} / \mathrm{l}$, they can exert toxic effects on non-target organisms (Rodriguez-Rodriguez et al., 2010; Grenni et al., 2013; Qurie et al., 2014). That is why preliminary studies on microorganisms able to degrade naproxen, as well as enzymes involved in its degradation, are so important.

The presented paper is the first report on the degradation of naproxen by gram-positive bacterium - Planococcus sp. S5. As we demonstrated previously, strain S5 is able to grow on salicylate, benzoate or phenol and express either catechol 1,2-dioxygenase or catechol 2,3-dioxygenase depending on the inductor (Łabużek et al., 2003; Hupert-Kocurek et al., 2012). Since naproxen, the derivative of naphthalene, may be metabolized by acetylic acid or benzoic acid as intermediates (Annweiler et al., 2000), the degradation potential of strain S5 suggests that this strain is a good candidate for naproxen biotransformation.

The chemical oxidation of naproxen in abiotic control, as well as adsorption of this drug on bacterial cells was not observed (data not shown). In monosubstrate culture, approximately $27.5 \%$ of naproxen was removed after 28 days. However, this compound was an insufficient carbon source for strain S5 and decrease in bacterial growth was observed (Fig. 1). This gave rise to the need for introducing an additional source of carbon into the culture. Due to the fact that aromatic plant compounds show a similar structure to naproxen, the use of such compounds as growth substrates may cause the induction of enzymes engaged in the metabolism of aromatic ring. Moreover, aromatic plant compounds are substrates naturally present in the environment. The results of studies on the transformation of naproxen in the presence of benzoate, 4-hydroxybenzoic acid, 3,4-dihydroxybenzoic acid or vanillic acid have shown that 4-hydroxybenzoic acid is a good growth substrate for cometabolic degradation of this drug. The increased efficiency of naproxen degradation was observed only in the presence of 4-hydroxybenzoic acid as an additional

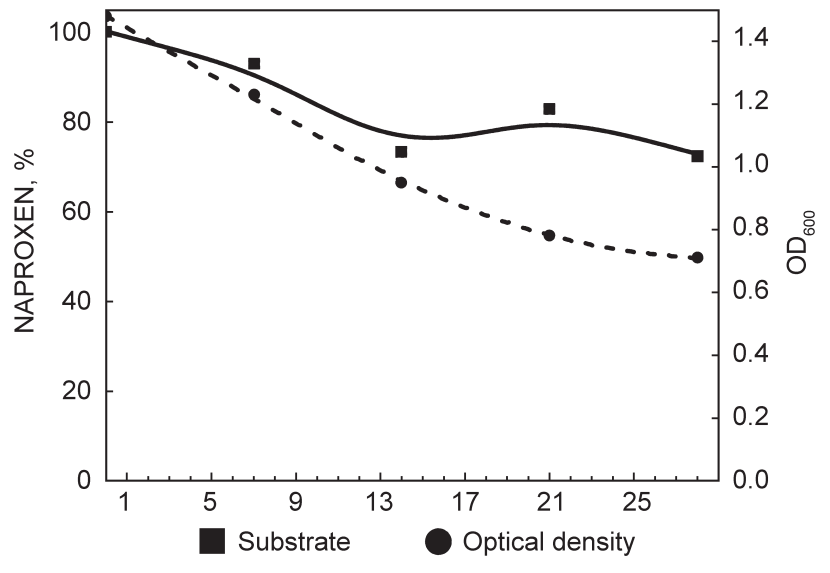

Fig. 1. Degradation of $6 \mathrm{mg} / \mathrm{l}$ naproxen by Planococcus sp. S5 and changes of microbial biomass monitored as optical density at $600 \mathrm{~nm}$

carbon source (Fig. 2). This confirms the results of our studies on nitrophenol degradation by Stenotrophomonas maltophilia KB2. Addition of 4-hydroxybenzoic acid into the culture allowed the transformation of about $30 \%$ of mononitrophenols (Greń et al., 2010).

Induction of degradation enzyme. Knowledge on enzymes engaged in naproxen degradation by microorganisms is very limited. Therefore, the aim of our study was to determine if/how the presence of naproxen affects the induction of key enzymes in aromatic degradation pathways. Planococcus sp. S5 is known to synthesizes two types of catechol dioxygenases: catechol 1,2-dioxygenase (in the presence of salicylate, benzoate or low concentration of phenol) and catechol 2,3-dioxygenase which synthesis is induced by salicylate or phenol (Łabużek et al., 2003; Hupert-Kocurek et al., 2012). Due to the low biomass obtained in the culture of strain S5 with naproxen as the only carbon source, as well as very low rate of naproxen degradation in the cultures with benzoate, 3,4-dihydroxybenzoic acid or vanillic acid as a growth substrate, degradation enzymes were isolated from cells grown in the presence of 4-hydroxybenzoate or 4-hydroxybenzoate and naproxen. After growth of the strain with 4-hydroxybenzoate activity of monooxygenase, hydroxyquinol 1,2-dioxygenase, protocatechuate 3,4-dioxygenase and gentisate 1,2-dioxygenase was observed (Table I, Fig. 3A). Monooxygenase is known to be engaged in hydroxylation of the aromatic ring of 4-hydroxybenzoate to 3,4-dihydroxybenzoic acid or 1,2,4-benzenotriol (Sze and Dagley, 1984; Eppink et al., 1997; Wang et al., 2002). The aromatic ring of 3,4-dihydroxybenzoate formed as a result of monooxygenase activity may be then cleaved by protocatechuate 3,4-dioxygenase, whereas degradation of 1,2,4-benzenetriol is catalyzed by hydroxyquinol 1,2-dioxygenase (Sze and Dagley, 1984; Park et al., 2006). Additionally, hydroxylation of 4-hydroxybenzoate may lead to gentisic acid formation 

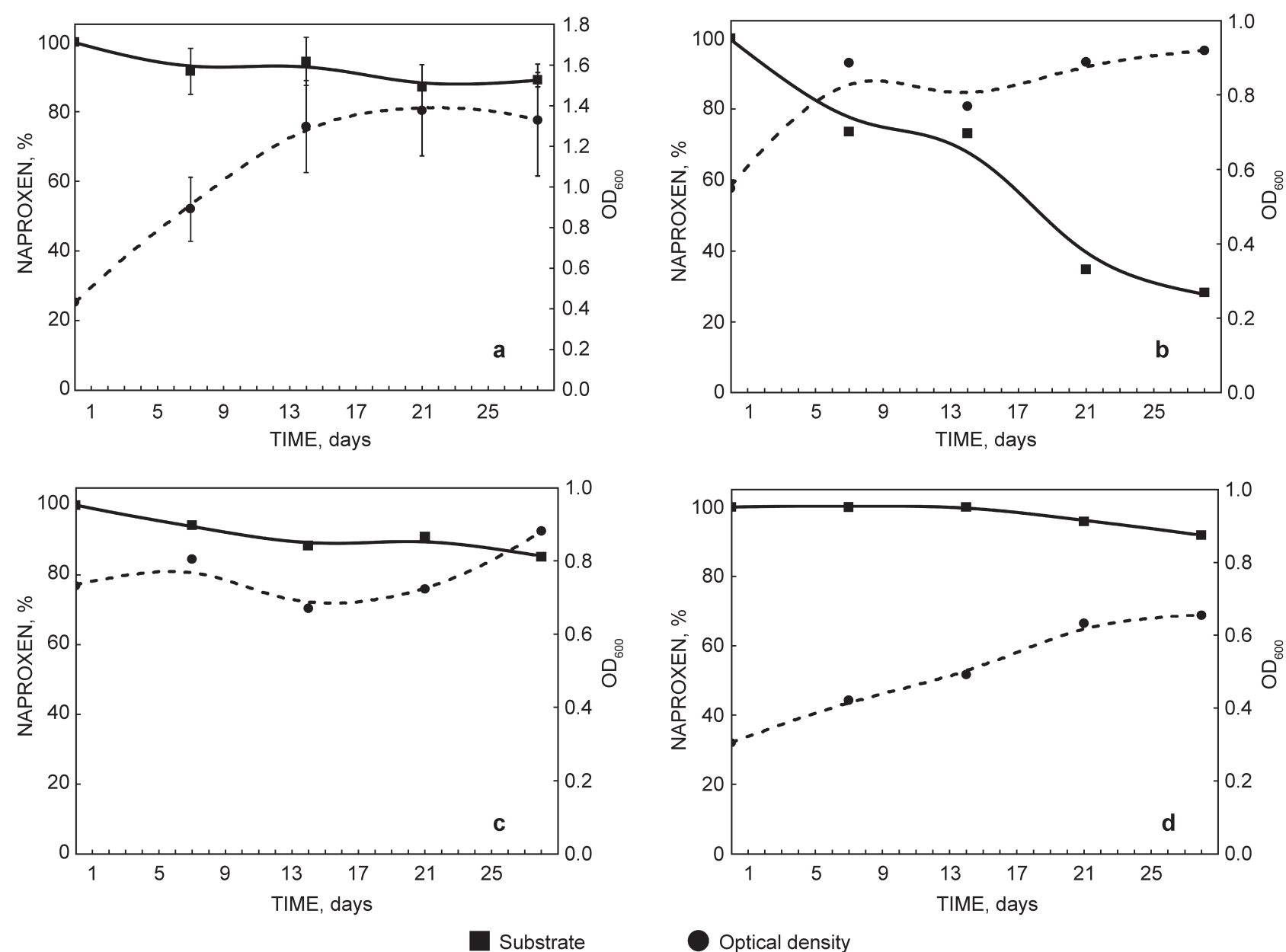

Fig. 2. Degradation of $6 \mathrm{mg} / \mathrm{l}$ naproxen by Planococcus sp. $\mathrm{S} 5$ in cometabolic systems and changes of microbial biomass monitored as optical density at $600 \mathrm{~nm}$ ( $\mathrm{a}$ - with $3 \mathrm{mM}$ benzoate; $\mathrm{b}$ - with $3 \mathrm{mM}$ 4-hydroxybenzoate; $\mathrm{c}$ - with $3 \mathrm{mM}$ 3,4-dihydroxybenzoate; $\mathrm{d}$ - with $3 \mathrm{mM}$ vanillic acid)

that is connected with the intramolecular migration (NIH Shift) of carboxylic group (Fairley et al., 2002; Deveryshetty et al., 2007). After growth of Planococcus

\section{Table I}

Specific activity of enzymes in the presence of 4-hydroxybenzoate or naproxen and 4-hydroxybenzoate

\begin{tabular}{|l|c|c|}
\hline \multirow{2}{*}{\multicolumn{1}{|c|}{ Enzyme }} & \multicolumn{2}{c|}{$\begin{array}{c}\text { Specific enzyme activity } \\
\text { (U/mg protein) }\end{array}$} \\
\cline { 2 - 3 } & 4 -HB & $\begin{array}{c}\text { naproxen } \\
+4 \text { - } \mathrm{HB}\end{array}$ \\
\hline monooxygenase & $25.74 \pm 1.90$ & $25.66 \pm 7.40$ \\
\hline naphthalene dioxygenase & $0.0 \pm 0.0$ & $0.0 \pm 0.0$ \\
\hline hydroxyquinol 1,2-dioxygenase & $46.56 \pm 0.0$ & $215.25 \pm 90.74$ \\
\hline catechol 1,2-dioxygenase & $0.0 \pm 0.0$ & $0.0 \pm 0.0$ \\
\hline catechol 2,3-dioxygenase & $0.0 \pm 0.0$ & $0.0 \pm 0.0$ \\
\hline protocatechuate 3,4-dioxygenase & $58.55 \pm 0.0^{*}$ & $30.47 \pm 2.12^{*}$ \\
\hline protocatechuate 4,5-dioxygenase & $0.0 \pm 0.0^{*}$ & $3.68 \pm 1.74^{*}$ \\
\hline gentisate 1,2-dioxygenase & $104.16 \pm 29.46^{*}$ & $0.0 \pm 0.0^{*}$ \\
\hline
\end{tabular}

* The asterisk indicates the values of enzymes activities which differ significantly $(\mathrm{p}<0.05)$ in dependence on the growth substrate sp. S5 with 4-hydroxybenzoate and naproxen changes in the activity of enzymes was observed (Table I, Fig. 3B). Activity of hydroxyquinol 1,2-dioxygenase increased approximately fourfold, while protocatechuate 3,4-dioxygenase and gentisate 1,2-dioxygenase, enzymes engaged in 4-hydoxybenzoate cleavage, were inhibited (Table I). As it is shown in Table I, in the presence of naproxen, protocatechuate 3,4-dioxygenase showed about $52 \%$ of its initial activity while gentisate 1,2-dioxygenase was completely inhibited. The increase in hydroxyquinol 1,2-dioxygenase activity could be connected with the engagement of this enzyme in naproxen degradation (Wojcieszyńska et al., 2014). Decrease of protocatechuate 3,4-dioxygenase activity was observed by Luo etal. (2008) in the presence of naphthalene, which is the structural mimetic of naproxen. However, in Planococcus sp. S5 culture with naproxen and 4-hydroxybenzoic acid activity of protocatechuate 4,5-dioxygenase was observed (Table I). Activity of this enzyme was also observed by Yun et al. (2004) during their studies on 4-hydroxybenzoic acid degradation. We assume that induction of protocatechuate 4,5-dioxygenase 
A<smiles>O=C(O)c1ccc(O)cc1</smiles>

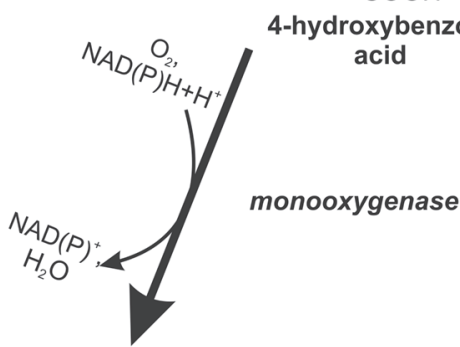<smiles>O=C(O)c1cc(O)ccc1O</smiles>

$\overbrace{\mathrm{O}}^{\mathrm{COOH}}$

maleylpyruvic

acid

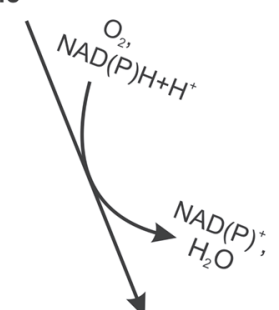

$\mathrm{OH}_{\mathrm{OH}}^{\mathrm{COOH}}$

protocatechuic

acid

Fig. 3. Suggested pathways of aromatic compounds degradation in Planococcus sp. S5 (a - monosubstrate culture with 4-hydroxybenzoate as a sole carbon source; b - cometabolic culture with 4-hydroxybenzoate as a carbon source and naproxen as a cometabolite)
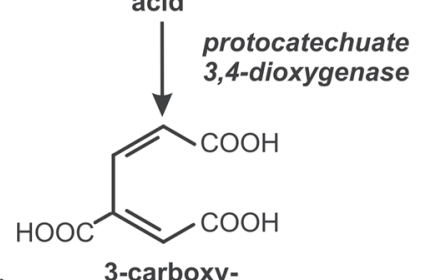

TCA

-cis, cis-muconic acid

B<smiles>O=C(O)c1ccc(O)cc1</smiles>

$+$<smiles>COc1ccc2cc(C(C)C)ccc2c1</smiles>

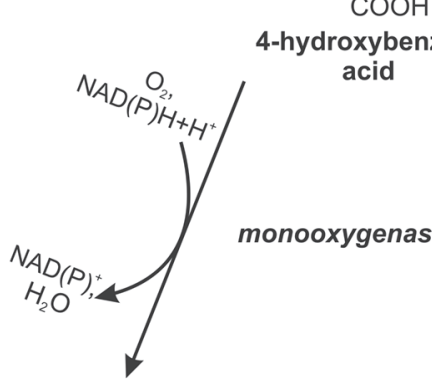

roxybenzoic

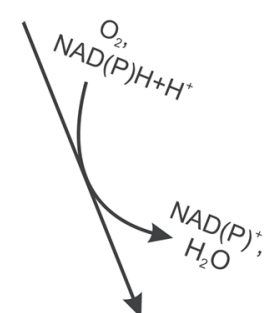<smiles>O=C(O)c1ccccc1O</smiles>

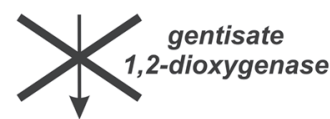

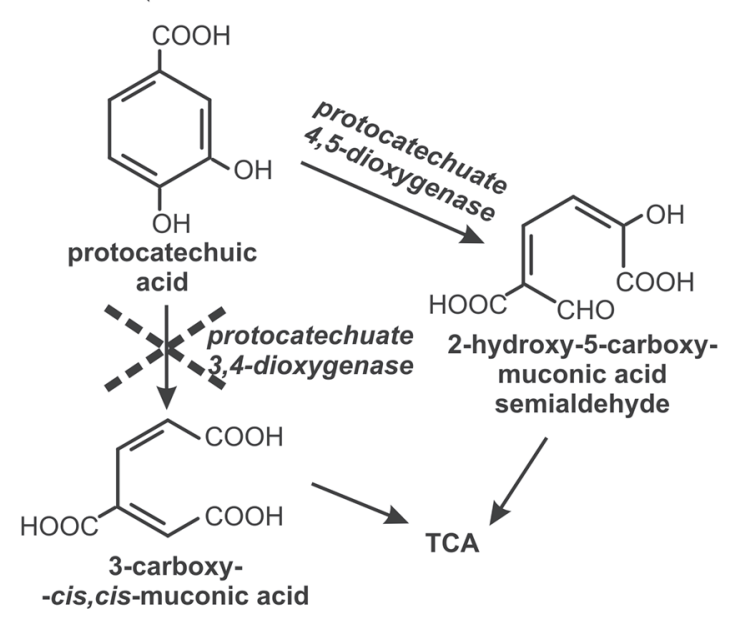<smiles>CC(C)c1ccc2c(O)c(O)c(O)c(O)c2c1</smiles><smiles>CC(=O)c1ccc(C(O)=C(O)C(=O)O)c(C(=O)O)c1</smiles> 
in the presence of naproxen and 4-hydroxybenzoate could be the response of bacterial strain to stress connected with inhibition of the main enzyme engaged in 4-hydroxybenzoate degradation (Fig. 3).

In conclusion, Planococcus sp. S5 has the ability of efficient degradation of naproxen in the presence of 4-hydroxybenzoate as a carbon source. In this condition, activity of monooxygenase, hydroxyquinol 1,2-dioxygenase, and two different protocatechuate dioxygenases is observed. The presence of various metabolic pathways and induction of different oxygenases involved in the degradation of aromatic compounds enable the use of Planococcus sp. S5 in the degradation of various aromatic pollutants including non-steroidal anti-inflammatory drugs.

\section{Acknowledgments}

This work was financed by the National Science Centre (Poland), granted on the basis of decision DEC-2013/09/B/NZ9/00244.

\section{Literature}

Annweiler E., H.H. Richnow, G. Antranikian, S. Hebenbrock, C. Garms, S. Franke, W. Francke and W. Michaelis. 2000. Naphthalene degradation and incorporation of naphthalene-derived carbon into biomass by the thermophile Bacillus thermoleovorans. App. Environ. Microbiol. 66: 518-523.

Cidaria D., F. Deidda and A. Bosetti. 1994. A rapid method for naphthalene dioxygenase assay in whole cells of naphthalene cisdihydrodiol dehydrogenase blocked Pseudomonas fluorescens: Screening of potential inducer of dioxygenase activity. Appl. Microbiol. Biotechnol. 41: 689-693.

Deveryshetty J., V. Suvekbala, G. Varadamshetty and P.S. Phale. 2007. Metabolism of 2-, 3- and 4-hydroxybenzoates by soil isolates Alcaligenes sp. strain PPH and Pseudomonas sp. strain PPD. FEMS Microbiol. Lett. 268: 59-66.

Divari S., F. Valetti, P. Caposito, E. Pessione, M. Cavaletto, E. Griva, G. Gribaudo, G. Gilardi and C. Giunta. 2003. The oxygenase component of phenol hydroxylase from Acinetobacter radioresistens S13. J. Biochem. 270: 2244-2253.

Eppink M.H., S.A. Boeren, J. Vervoort and W.J. van Berkel. 1997. Purification and properties of 4-hydroxybenzoate 1-hydroxylase (decarboxylating), a novel flavin adenine dinucleotide-dependent monooxygenase from Candida parapsilosis CBS604. J. Bacteriol. 179: 6680-6687.

Fairley D.J., D.R. Boyd, N.D. Sharma, C.C.R. Allen, P. Morgan and M.J. Larkin. 2002. Aerobic metabolism of 4-hydroxybenzoic acid in Archaea via an unusual pathway involving an intramolecular migration (NIH shift). Appl. Environ. Microbiol. 68: 6246-6255. Feng Y., H.E. Khoo and Ch.L. Poh. 1999. Purification and characterization of gentisate 1,2-dioxygenases from Pseudomonas alcaligenes NCIB 9867 and Pseudomonas putida NCIB 9869. Appl. Microbiol. Biotechnol. 65:946-950.

Ghareib H.R.A., M.S. Abdelhamed and A.H. Ibrahim. 2010. Antioxidative effects of the acetone fraction and vanillic acid from Chenopodium murale on tomato plants. Weed. Biol. Manag. 10: 64-72.

Greń I., D. Wojcieszyńska, U. Guzik, M. Perkosz and K. HupertKocurek. 2010. Enhanced biotransformation of mononitrophenols by Stenotrophomonas malthophilia KB2 in the presence of aromatic compounds of plant origin. World J. Microbiol. Biotechnol. 26: 289-295.
Grenni P., L. Patrolecco, N. Ademollo, A. Tolomei and A.B. Caracciolo. 2013. Degradation of gemfibrozil and naproxen in a river water ecosystem. Microchem. J. 107: 158-164.

Grenni P., L. Patrolecco, N. Ademollo, M. Di Lenola and A.B. Caracciolo. 2014. Capability of the natural microbial community in a river water ecosystem to degrade the drug naproxen. Environ. Sci. Pollut. Res. 21: 13470-13479.

Hou Ch.T., M.O. Lillard and R.D. Schwartz. 1976. Protocatechuate 3,4-dioxygenase from Acinetobacter calcoaceticus. Biochemistry 15: 582-588.

Hupert-Kocurek K., U. Guzik and D. Wojcieszyńska. 2012. Characterization of catechol 2,3-dioxygenase from Planococcus sp. strain S5 induced by high phenol concentration. Acta Biochim. Pol. 59: 345-351. Kakkar S. and S. Bais. 2014. A review on protocatechuic acid and its pharmacological potential. ISRN Pharmacol. 26(2014): 952943. Kulkarni M. and A. Chaudhari. 2006. Biodegradation of p-nitrophenol by P. putida. Biores. Technol. 97: 982-988.

Lahti M. and A. Oikari. 2011. Microbial transformation of pharmaceuticals naproxen, bisoprolol, and diclofenac in aerobic and anaerobic environments. Arch. Environ. Contam. Toxicol. 61: 202-210.

Luo S., J.J. Zhang and N.Y. Zhou. 2008. Molecular cloning and biochemical characterization of protocatechuate 3,4-dioxygenase in Burkholderia sp. NCIMB 10467. Microbiology 35: 712-719.

Labużek S., K. Hupert-Kocurek and M. Skurnik. 2003. Isolation and characterization of new Planococcus sp. strain able for aromatic hydrocarbons degradation. Acta Microbiol. Pol. 52: 395-404.

Marco-Urrea E., M. Pérez-Trujillo, P. Blánquez, T. Vicent and G. Caminal. 2010. Biodegradation of the analgesic naproxen by Trametes versicolor and identification of intermediates using HPLCDAD-MS and NMR. Biores. Technol. 101: 2159-2166.

Park S.H., J.W. Kim, S.H. Yuo, S.H. Leem, H.Y. Kahng and S.I. Kim. 2006. Characterization of $\beta$-ketoadipate pathway from multi-drug resistance bacterium, Acinetobacter baumannii DU202 by proteomic approach. J. Microbiol. 44: 632-640.

Quintana J.B., S. Weiss and T. Reemtsma. 2005. Pathways and metabolites of microbial degradation of selected acidic pharmaceutical and their occurrence in municipal wastewater treated by membrane bioreactor. Water Res. 39: 2654-2664.

Qurie M., M. Khamis, F. Malek, S. Nir, S.A. Bufo and J. Abbadi. 2014. Stability and removal of naproxen and its metabolite by advanced membrane wastewater treatment plant and micelle-clay complex. Clean Soil Air Water 42: 594-600.

Rodriguez-Rodriguez C.E., E. Marco-Urrea and G. Caminal. 2010. Degradation of naproxen and carbamazepine in spiked sludge by slurry and solid-phase system. Biores. Technol. 101: 1159-2266. Sze I.S. and S. Dagley. 1984. Properties of salicylate hydroxylase and hydroxyquinol 1,2-dioxygenase purified from Trichosporon cutaneum. J. Bacteriol. 159: 353-359.

Wang J., M. Ortiz-Maldonado, B. Entsch, V. Massey, D. Ballou and D.L. Gatti. 2002. Protein and ligand dynamics in 4-hydroxybenzoate hydroxylase. PNAS 99: 608-613.

Wei M., J.J. Zhang, H. Liu and N.Y. Zhou. 2010. para-Nitrophenol 4-monooxygenase and hydroxyquinol 1,2-dioxygenase catalyze sequential transformation of 4-nitrocatechol in Pseudomonas sp. strain WBC-3. Biodegradation 21: 915-921.

Wojcieszyńska D., U. Guzik, I. Greń, M. Perkosz and K. HupertKocurek. 2011. Induction of aromatic ring - cleavage dioxygenases in Stenotrophomonas maltophilia strain KB2 in cometabolic systems. World J. Microbiol. Biotechnol. 27: 805-811.

Wojcieszyńska D., D. Domaradzka, K. Hupert-Kocurek and U. Guzik. 2014. Bacterial degradation of naproxen-undisclosed pollutant in the environment. J. Environ. Manage. 145: 157-161.

Yun S.H., Ch.Y. Yun and S.I. Kim. 2004. Characterization of protocatechuate 4,5-dioxygenase induced from $p$-hydroxybenzoatecultured Pseudomonas sp. K82. J. Microbiol. 42: 152-155. 